Utah State University

DigitalCommons@USU

Psychology Student Research

Psychology Student Works

2021

\title{
Weight-Related Psychological Inflexibility as a Mediator Between Weight Self-Stigma and Health-Related Outcomes
}

Julie M. Petersen

Utah State University, julie.petersen@aggiemail.usu.edu

Carrie Durward

Utah State University, carrie.durward@usu.edu

Michael Levin

Utah State University, mike.levin@usu.edu

Follow this and additional works at: https://digitalcommons.usu.edu/psych_stures

Part of the Psychology Commons

\section{Recommended Citation}

Petersen, J.*, Durward, C., Levin, M.E. (In Press). Psychological inflexibility as a mediator between weight self-stigma and health-related outcomes. The Bulletin of the Menninger Clinic.

This Article is brought to you for free and open access by the Psychology Student Works at DigitalCommons@USU. It has been accepted for inclusion in Psychology Student Research by an authorized administrator of DigitalCommons@USU. For more information, please contact digitalcommons@usu.edu.

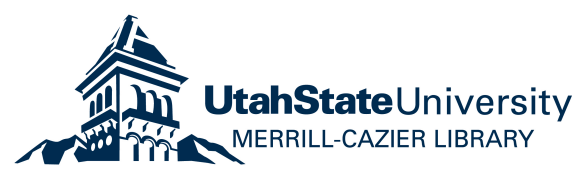


Weight-related psychological inflexibility, weight self-stigma, and health-related outcomes

Weight-related psychological inflexibility as a mediator between weight self-stigma and healthrelated outcomes

Julie M. Petersen B.S., Carrie Durward, Ph.D., R.D., Michael Levin, Ph.D.

Utah State University

Correspondence concerning this article should be addressed to Julie Petersen, Department of Psychology, Utah State University, 2810 Old Main Hill, Logan, UT 84322, United States.

Phone: (435) 527-5140, Email: Julie.Petersen@aggiemail.usu.edu. 


\begin{abstract}
Weight self-stigma, the internalization of negative societal stereotypes, is a problem amongst populations with high weight. Weight self-stigma is associated with psychological inflexibility and maladaptive health-related behaviors. In this study, we explore how weightrelated psychological inflexibility may influence weight self-stigma and health-related outcomes in 79 adults with high weight. Participants were primarily white $(92.4 \%)$ and female $(82.3 \%)$, with an average age of 39.56 and average body mass index of 33.78. The present study uses baseline, self-report data from a larger trial. Results indicate that weight self-stigma was negatively correlated with maladaptive eating behaviors, weight, and mental health. Weightrelated psychological inflexibility was found as a significant mediator for the relationship between weight self-stigma and emotional eating, sedentary behavior, and mental health. Weight-related psychological inflexibility did not mediate the relationships between weight selfstigma and other eating measures and physical activity. These results support targeting weightrelated psychological inflexibility and weight self-stigma in interventions.
\end{abstract}

Keywords: weight-self stigma, weight-related psychological inflexibility, maladaptive eating, obesity 


\section{Introduction}

Stigma against individuals with high weight is pervasive in American society (Puhl \& Heuer, 2010). Harmful labels and associations such as laziness, lower intelligence, and lack of discipline are frequently related to people with high weight (Wang, Brownell, \& Wadden, 2004). Discrimination against people with high weight occurs through daily experiences of judgement or harassment, as well as through employment, healthcare, and educational systems (Puhl \& Heuer, 2009). For example, 53\% of individuals with high weight in one study reported experiencing stigma and receiving inappropriate comments from doctors and nurses in healthcare settings (Puhl \& Brownell, 2006). Such stigmatizing attributions are associated with low selfesteem, low life satisfaction and negative self-judgments (e.g., shame and guilt; Annis, Cash, \& Hrabosky, 2004).

Chronic, pervasive experiences of stigmatization and discrimination associated with high weight may cause individuals with high weight to develop internalized self-stigma about weight. Self-stigma is the individual internalization of discriminatory or negative stereotypes implicated by society (Luoma \& Platt, 2015). Self-stigma increases as the individual regularly devalues themselves and fears that others will discriminate or stigmatize them (Lillis, Luoma, Levin, \& Hayes, 2010). While self-stigma can arise from a variety of negative or discriminatory experiences, weight self-stigma is highly prevalent in individuals with high weight, observed in up to $40 \%$ of such individuals (Puhl, Himmelstein \& Quinn, 2018). Weight self-stigma is associated with psychological maladjustment, isolation, poor functioning, depression, and lowered self-reassurance in populations with high weight (Carels et al., 2014; Palmeira, PintoGouveia, \& Cunha, 2016; Wott \& Carels, 2010). Weight self-stigma is also highly implicated in physical health; greater weight self-stigma is associated with overall physical health impairment 
and greater BMI, even when controlling for health-related quality of life, age, and other physical health factors (Latner, Barile, Durso, \& O’Brien, 2014; Latner, Durso, \& Mond, 2013). Those with greater weight self-stigma are more likely to engage in unhealthy behaviors such as excess eating (Carels et al., 2009; Puhl \& Suh, 2015). Individuals with high weight self-stigma may also be less likely to engage in physical activity due to avoidance of exercise, especially since exercise may trigger fears of enacted stigma (Puhl \& Suh, 2015; Vartanian \& Novak, 2011). This may be why individuals with high weight who report high weight self-stigma also report poorer physical health and quality of life than other individuals with high weight (Latner et al., 2014). Weight self-stigma has similarly been found to contribute to a variety of problematic and unhealthy eating habits. On the whole, weight stigma and weight self-stigma are associated with greater binge eating and food consumption (Carels et al., 2014; Palmeira, Pinto-Gouveia, Cunha, \& Carvalho, 2017; Puhl, Moss-Racusin, \& Schwartz, 2007; Wang et al., 2004). For example, women with high weight and binge eating disorder (BED) have significantly higher levels of weight self-stigma than women with high weight who do not have BED (Palmeira et al., 2017). Weight self-stigma is also a documented mediator between discriminatory experiences and eating disturbances in individuals with high weight, demonstrating that discriminatory experiences based on weight may trigger maladaptive eating behaviors more if weight selfstigma is high (Durso et al., 2012). With the evident impact of weight self-stigma on eating behavior, there is a need to fully understand how to break the associations between weight-based discrimination, maladaptive eating, and weight self-stigma in order to best develop and deliver effective interventions for weight loss and health improvement.

Psychological inflexibility may be a relevant construct to explore in order to best develop such interventions. Psychological inflexibility is a transdiagnostic process during which an 
individual's thoughts and feelings rigidly dictate behavior, typically resulting in avoidance instead of engagement with valued behaviors (Hayes, Luoma, Bond, Masuda, \& Lillis, 2006). Weight-related psychological inflexibility is when thoughts and feelings around weight (e.g., "I need to lose weight" or "I always need to clean my plate") rigidly and excessively govern one's behavior (e.g., eating, exercise, avoiding activities). Weight self-stigma has consistently been found to correlate with general psychological inflexibility (Krafft, Ferrell, Levin, \& Twohig, 2018). General psychological inflexibility and weight-related psychological inflexibility are also significantly related to binge eating — a behavior which past research has connected to weight self-stigma (Krafft et al., 2018; Palmeira et al., 2017). Thus, it is possible that weight-related psychological inflexibility specifically may act as a mediating factor between weight self-stigma and health-related outcomes in individuals with high weight.

Given the association between weight self-stigma and psychological inflexibility, weight self-stigma may perpetuate psychologically inflexible behaviors, thereby producing lowered quality of life. For example, self-stigmatizing thoughts about one's weight may motivate rigid, avoidant responses that lead to binge eating, avoiding exercise, or other maladaptive behaviors, ultimately producing emotional or health-related consequences that lower quality of life (Durso et al., 2012). However, there is a dearth of research exploring whether weight self-stigma contributes to psychological inflexibility, and whether this may account for how weight selfstigma leads to maladaptive behaviors and decreased quality of life.

In the present study, we explore the associations between weight self-stigma, weightrelated psychological inflexibility, and health-related outcomes. We hypothesized that weightrelated psychological inflexibility would mediate the relationship between weight self-stigma 
and health-related outcomes, such that greater weight self-stigma potentially adds to weightrelated psychological inflexibility and thereby poorer health.

\section{Methods}

\section{Participants}

The sample consisted of 79 adults with high weight living in [removed for masked review] who were interested in participating in an online program to improve eating and physical activity. Participants were required to have a BMI of 25 or higher and have regular access to internet in order to participate. Recruitment consisted of Reddit postings on [removed for masked review]-oriented subreddits (pages), email announcements, and university Cooperative Extension contacts and activities throughout the state. Participants were primarily white $(92.4 \%)$ and female $(82.3 \%)$, with an average age of $39.56(S D=12.12)$ and an average body mass index $(\mathrm{BMI})$ of $33.78(S D=5.69)$. The majority of participants were working full time $(83.5 \%)$ with a household income of $\$ 60,000-79,999$.

\section{Procedures}

The study used baseline data collected as a part of a randomized controlled trial evaluating an online course for health behavior change. All study procedures were completed online or over the phone, primarily on the Qualtrics research platform. Once all initial questionnaires had been completed, participants were randomized to participate in the online course or onto an 8-week waitlist. However, this study only reports the baseline data collected prior to participants being randomized to an experimental condition.

\section{Measures}


Demographics. Participants were asked to report standard demographics, as well as height (in feet and inches) and weight (in pounds). Using self-reported height and weight, body mass index (BMI) was calculated.

Weight Self-stigma Questionnaire (WSSQ; Lillis, Luoma, Levin, Hayes, 2010). The WSSQ was included as a measure of internalized weight self-stigma, with two subscales of selfdevaluation and fear of enacted stigma. Participants are asked to rate 12 items on a 5-point Likert scale $(1=$ completely disagree, $5=$ completely agree $)$, with higher scores indicating greater weight self-stigma. Some example items from the WSSQ include "I caused my weight problems" and "I'll always go back to being overweight." The WSSQ has demonstrated good reliability and validity (Lillis et al., 2010). The Cronbach's alpha for the current sample was .91. Acceptance and Action Questionnaire for Weight (AAQ-W; Lillis, Hayes, \& Levin, 2011). The AAQ-W was included as a measure of psychological inflexibility with weight-related thoughts and feelings. Participants are asked to rate 22 items on a 7-point Likert scale, with higher scores indicating greater weight-based psychological inflexibility. Some example items from the AAQ-W include "My eating urges control me" and "When I have negative feelings, I use food to make myself feel better." The AAQ-W has demonstrated good reliability and clinical sensitivity (Palmeira, Cunha, Pinto-Gouveia, Carvalho, \& Lillis, 2016). The Cronbach's alpha for the current sample was .79.

Three Factor Eating Questionnaire (TFEQ; Stunkard \& Messick, 1985). The TFEQ is an 18-item measure of cognition and behavior surrounding eating. The TFEQ is composed of three subscales, with higher scores indicating greater levels of each construct: cognitive restraint, disinhibition, and emotional eating. The cognitive restraint subscale assesses the extent to which an individual is able to control food intake (e.g., "I consciously hold back at meals in order not to 
gain weight."), the disinhibition subscale assesses loss of control while eating (e.g., "Sometimes when I start eating, I just can't seem to stop.”), and the emotional eating scale measures cravings and other feelings associated with hunger (e.g., "When I feel lonely, I console myself by eating.”) The TFEQ has demonstrated good convergent and discriminant validity (Karlsson, Persson, Sjöström, \& Sullivan, 2000). The Cronbach's alpha for the current sample was .86. International Physical Activity Questionnaire (IPAQ; Booth, 2000). The IPAQ is a fourpart questionnaire measuring weekly physical activity. The IPAQ assesses four domains of physical activity (work-related, transportation, housework/gardening, and leisure-time) in the last week. Participants are asked to report the number of days and daily hours spent per week in each domain of physical activity. For example, participants are asked "During the last 7 days, on how many days did you walk for at least 10 minutes at a time?" The IPAQ has demonstrated acceptable validity for evaluating weekly physical activity (Hagströmer, Oja, \& Sjöström, 2006). Total IPAQ scores are based in the standardized units of Metabolic Equivalent Task (MET) minutes per week. METs were calculated for each domain and intensity level and then summed into a total score. Time was limited to a maximum of 3 hours in order to minimize outliers.

General Health Questionnaire (GHQ; Wemeke, Goldberg, Yalcin, \& Üstün, 2000). The GHQ is a 12-item measure of general psychological distress. Participants rate each item on a 4point Likert scale; higher scores on the GHQ indicate greater mental health. Some example items from the GHQ include "Have you recently felt constantly under strain?" and "Have you recently been thinking of yourself as a worthless person?" Previous studies report the GHQ with adequate reliability and validity (Banks, 1980). The Cronbach's alpha for the current sample was .89.

\section{Analytic Plan}


All variables were checked for skewness and kurtosis prior to analyses, with all variables approximating a normal distribution besides the GHQ. A logarithmic transformation was used for the GHQ to approximate a normal distribution. General correlations were calculated between all measures. A series of mediational analyses then tested whether weight-related psychological inflexibility mediates the effects of weight self-stigma on eating and health-related outcomes. Theoretically, weight self-stigma could contribute to inflexible, maladaptive responses to internal experiences related to weight, which would lead to problematic eating behaviors and lower quality of life. Because of its high correlation with weight self-stigma and various health-related outcomes in prior research, BMI was included as a covariate in all mediational models. Analyses were conducted using the cross product of coefficients test and with all health-related outcomes regardless of correlation significance.

\section{Results}

\section{Baseline correlations}

Overall, weight self-stigma was correlated with disinhibition, emotional eating, weight, and overall mental health, such that higher self-stigma was related to more negative outcomes (See Table 1). However, weight self-stigma was not correlated with physical activity. Psychological inflexibility with weight was largely correlated with the same variables with the exception of self-reported BMI (which only correlated with weight self-stigma) and self-reported sitting time (which only correlated with inflexibility). Self-reported BMI was correlated with both weight self-stigma and overall mental health. Results suggest weight self-stigma and inflexibility are related to a variety of eating and health patterns, particularly those related to regulation of eating.

\section{Testing weight-related psychological inflexibility as a mediator for weight self-stigma}


BMI was included as a covariate due to its correlation with both GHQ mental health and weight self-stigma. Significant mediation effects were found for TFEQ emotional eating, GHQ mental health, and IPAQ sedentary behavior (see Table 2). Weight-related psychological inflexibility significantly mediated the relation between weight self-stigma and emotional eating, along with the relation between weight self-stigma and mental health, such that weight selfstigma no longer predicted outcomes when controlling for the mediator (and with significant $a, b$, and c paths). Although there was no significant $\mathrm{c}$ path, a significant mediation effect was also found for weight-related psychological inflexibility with IPAQ sedentary behavior. The AAQ-W did not mediate the relation between weight self-stigma and disinhibition, cognitive restraint, or physical activity. Mediation effects were all tested with and without BMI as a covariate; however, no differences in results were found with or without BMI.

An additional series of mediational models tested the direction of mediation by reversing the mediator and predictor variable. In each case, the WSSQ weight self-stigma did not mediate the relation between the AAQ-W inflexibility and outcomes, possibly due to the lack of a significant $b$ path effect (see Table 2).

\section{Discussion}

This study sought to investigate the role of weight-related psychological inflexibility as a mediator in the relations between weight self-stigma, eating behaviors, and health-related outcomes. Results indicated weight self-stigma was related to weight, eating behaviors and mental health, but not physical activity as self-reported on the IPAQ. Furthermore, weightrelated psychological inflexibility was found as a mediator between weight self-stigma and three outcomes (emotional eating, sedentary behavior, and mental health). 
Consistent with prior research, weight self-stigma was correlated with disinhibition, emotional eating, weight, and overall mental health (Carels et al., 2014; Palmeira, PintoGouveia, Cunha, \& Carvalho, 2017; Puhl, Moss-Racusin, \& Schwartz, 2007; Wang et al., 2004). Thus, there seems to be a connection between weight self-stigma and maladaptive eating. This theory is further reinforced by experimental research findings in which females with high weight ate three times more kilocalories after being primed about their weight as compared to those receiving a neutral prime (Schvey, Puhl, \& Brownell, 2011).

On the other hand, weight self-stigma was not correlated with physical activity in the present study. The lack of relationship with physical activity does not align with prior research connecting weight self-stigma to avoidance of exercise (Puhl \& Suh, 2015; Vartanian \& Novak, 2011). It is possible that a more nuanced understanding is required for how weight self-stigma manifests in the context of physical activity. For example, perhaps the presence of weight selfstigma alone does not interfere with the performance of physical activity, but the quality of the exercise. However, the present study is limited, particularly because it only used a self-report of physical activity. A more accurate measure of physical activity (e.g., data from a physical activity tracker) may provide a better understanding of the relationship between physical activity and weight self-stigma.

A similar pattern of relationships was observed for weight-related psychological inflexibility, which was correlated with maladaptive eating behaviors (disinhibition and emotional eating), sedentary behaviors, and general mental health. These findings add to previous correlational research regarding psychological inflexibility and maladaptive eating (Palmeira et al., 2017). Psychological inflexibility with weight was additionally correlated with sedentary time, a component of physical activity, but not total physical activity. There is little 
research available on the associations between psychological inflexibility and physical activity. As previously discussed, this research gap speaks to the need for a more precise understanding of physical activity in relation to psychological variables - especially potential targets of psychological interventions.

Going beyond the correlational findings, psychological inflexibility with weight was found to mediate the effects of weight self-stigma on eating (emotional eating), sedentary behavior, and general mental health. The other eating variables' (disinhibition and cognitive restraint) relationship with weight self-stigma was not mediated by weight-related psychological inflexibility. Avoidant behaviors like emotional eating are common in individuals with increased psychological inflexibility related to weight, possibly explaining the significance of weightrelated psychological inflexibility when examining pathways between weight self-stigma and emotional eating, but not disinhibition or cognitive restraint. Similar to emotional eating, sedentary behavior may also be an avoidant response to self-stigmatizing thoughts. For example, an individual with high weight self-stigma may believe stigmatizing thoughts and negative societal assumptions related to individuals with high weight; a psychologically inflexible response to these beliefs may in turn contribute to elevated sedentary behaviors (e.g., playing video games rather than exercising) or emotional eating (e.g., eating to feel better when feeling hopeless about weight).

Given these findings, it is possible that weight self-stigma may maintain weight-related psychological inflexibility. The process of internalizing negative thoughts about weight and selfstigmatization could contribute to other maladaptive, inflexible responses to thoughts and feelings (e.g., responding to self-critical thoughts as literally true, attempts to avoid or suppress shame or other internal reactions about one's weight or appearance). This might subsequently 
lead to avoidance of health-related behaviors (e.g., exercise, healthy eating) and propagate maladaptive behaviors (e.g., emotional eating, excessive sedentary behavior) in an attempt to avoid weight-related thoughts and feelings. In turn, these effects may lead to and account for poor outcomes such as lower quality of life or poor general mental health (Durso et al., 2012).

\section{Implications for Practice}

These findings demonstrate that weight self-stigma and weight-related psychological inflexibility with weight may be important targets for health interventions. These models align with past research; a recent systematic review of acceptance and commitment therapy (ACT), an intervention targeting psychological inflexibility generally, for weight self-stigma suggests that decreasing weight-related psychological inflexibility overall may help in reducing weight selfstigma (Griffiths, Williamson, Zucchelli, Paraskeva, \& Moss, 2018). Thus, these findings provide support for research on health and weight-loss interventions incorporating methods designed to target weight-related psychological flexibility and weight self-stigma. Clinical practice may consider how internalized negative thoughts, especially regarding weight and selfstigmatization, may contribute to maladaptive health behaviors (e.g., emotional eating, avoidance of exercise) in an attempt to avoid weight-related or other negative internal experiences.

\section{Limitations}

There are limitations with this study. First, the small sample size and cross-sectional design prevent larger conclusions regarding directionality. Although the non-significant reversed mediational models provide further support for weight-related psychological inflexibility mediating the effects of weight self-stigma, this approach still has very limited causal implications. The smaller sample size may also have limited the analyses through a lack of power to detect smaller effects. A larger, more diverse sample may allow for a greater 
understanding and variation when exploring variable associations. Additionally, experimental or longitudinal paradigms may also have allowed for greater insight into how weight-related psychological inflexibility interferes with adaptive eating or physical activity. For example, using ecological momentary assessment for these same variables could provide key insight into understanding the role psychological flexibility may play in enhancing physical activity.

\section{Conclusion}

In summary, the present study supports the role of weight-related psychological inflexibility with weight as a mediator between weight self-stigma and emotional eating, sedentary behavior, and general mental health. Future research with diverse groups, greater power, and capability to test for directionality is needed in order to better understand how weight-related psychological inflexibility relates with these variables. On the whole, the present study provides innovative information when considering the improvement of health interventions. 
Funding: This work was supported by [removed for blind review]. 


\section{References}

Annis, N. M., Cash, T. F., \& Hrabosky, J. I. (2004). Body image and psychosocial differences among stable average weight, currently overweight, and formerly overweight women: The role of stigmatizing experiences. Body Image, 1(2), 155-167.

https://doi.org/10.1016/j.bodyim.2003.12.001

Booth, M. (2000). Assessment of physical activity: An international perspective. Research Quarterly for Exercise and Sport, 71(sup2), 114-120. https://doi.org/10.1080/02701367.2000.11082794

Carels, R A, Young, K. M., Wott, C. B., Harper, J., Gumble, A., Hobbs, M. W., \& Clayton, A. M. (2009). Internalized weight stigma and its ideological correlates among weight loss treatment seeking adults. Eating and Weight Disorders, 14(2-3), e92-7. https://doi.org/10.1007/BF03327805

Carels, Robert A., Burmeister, J., Oehlhog, M. W., Hinman, N., LeRoy, M., Bannon, E., ... Ashrafloun, L. (2014). Obese individuals and psychological maladjustment. Journal of Behavioral Addictions, 36(1), 1-13. https://doi.org/10.1007/s10865-012-9402-8.

Durso, L. E., Latner, J. D., \& Hayashi, K. (2012). Perceived discrimination is associated with binge eating in a community sample of non-overweight, overweight, and obese adults. Obesity Facts, 5(6), 869-880. https://doi.org/10.1159/000345931

Griffiths, C., Williamson, H., Zucchelli, F., Paraskeva, N., \& Moss, T. (2018). A systematic review of the effectiveness of acceptance and commitment therapy (ACT) for body image dissatisfaction and weight self-stigma in adults. Journal of Contemporary Psychotherapy, 48(4), 189-204. https://doi.org/10.1007/s10879-018-9384-0

Hagströmer, M., Oja, P., \& Sjöström, M. (2006). The International Physical Activity 
Questionnaire (IPAQ): A study of concurrent and construct validity. Public Health Nutrition, 9(6), 755-762. https://doi.org/10.1079/phn2005898

Hayes, S. C., Luoma, J. B., Bond, F. W., Masuda, A., \& Lillis, J. (2006). Acceptance and commitment therapy: Model, processes and outcomes. Behaviour Research and Therapy, $44(1), 1-25$.

Karlsson, J., Persson, L. O., Sjöström, L., \& Sullivan, M. (2000). Psychometric properties and factor structure of the Three-Factor Eating Questionnaire (TFEQ) in obese men and women. Results from the Swedish Obese Subjects (SOS) study. International Journal of Obesity, 24(12), 1715-1725. https://doi.org/10.1038/sj.ijo.0801442

Krafft, J., Ferrell, J., Levin, M. E., \& Twohig, M. P. (2018). Psychological inflexibility and stigma: A meta-analytic review. Journal of Contextual Behavioral Science, 7, 15-28. https://doi.org/10.1016/J.JCBS.2017.11.002

Latner, J. D., Barile, J. P., Durso, L. E., \& O’Brien, K. S. (2014). Weight and health-related quality of life: The moderating role of weight discrimination and internalized weight bias. Eating Behaviors, 15(4), 586-590. https://doi.org/10.1016/J.EATBEH.2014.08.014

Latner, J. D., Durso, L. E., \& Mond, J. M. (2013). Health and health-related quality of life among treatment-seeking overweight and obese adults: Associations with internalized weight bias. Journal of Eating Disorders, 1(1), 3. https://doi.org/10.1186/2050-2974-1-3

Lillis, J., Hayes, S. C., \& Levin, M. E. (2011). Binge eating and weight control: The role of experiential avoidance. Behavior Modification, 35(3), 252-264.

Lillis, J., Luoma, J. B., Levin, M. E., \& Hayes, S. C. (2010). Measuring weight self-stigma: The weight self-stigma questionnaire. Obesity, 18(5), 971-976. https://doi.org/10.1038/oby.2009.353 
Luoma, J. B., \& Platt, M. G. (2015). Shame, self-criticism, self-stigma, and compassion in acceptance and commitment therapy. Current Opinion in Psychology, 2, 97-101. https://doi.org/10.1016/J.COPSYC.2014.12.016

Palmeira, L., Cunha, M., Pinto-Gouveia, J., Carvalho, S., \& Lillis, J. (2016). New developments in the assessment of weight-related experiential avoidance (AAQW-Revised). Journal of Contextual Behavioral Science, 5(3), 193-200. https://doi.org/10.1016/j.jcbs.2016.06.001

Palmeira, L., Pinto-Gouveia, J., \& Cunha, M. (2016). The role of weight self-stigma on the quality of life of women with overweight and obesity: A multi-group comparison between binge eaters and non-binge eaters. Appetite, 105, 782-789. https://doi.org/10.1016/J.APPET.2016.07.015

Palmeira, L., Pinto-Gouveia, J., Cunha, M., \& Carvalho, S. (2017). Finding the link between internalized weight-stigma and binge eating behaviors in Portuguese adult women with overweight and obesity: The mediator role of self-criticism and self-reassurance. Eating Behaviors, 26, 50-54. https://doi.org/10.1016/j.eatbeh.2017.01.006

Puhl, R.M, \& Brownell, K.D. (2006). Confronting and coping with weight stigma: An investigation of overweight and obese adults. Obesity, 14, 1802-1815.

Puhl, R.M., \& Heuer, C. A. (2009). The stigma of obesity: A review and update. Obesity, 17(5), 941-964. https://doi.org/10.1038/oby.2008.636

Puhl, R.M. \& Heuer, C.A. (2010). Obesity stigma: Important considerations for public health. American Journal of Public Health, 100, 1019-1028.

Puhl, R.M., Himmelstein, M.S. \& Quinn, D.M. (2018). Internalizing weight stigma: Prevalence and sociodemographic considerations in US adults. Obesity, 26, 167-175.

Puhl, R. M., Moss-Racusin, C. A., \& Schwartz, M. B. (2007). Internalization of weight bias: 
Implications for binge eating and emotional well-being. Obesity, 15(1), 19-23. https://doi.org/10.1038/oby.2007.521

Puhl, R., \& Suh, Y. (2015). Health consequences of weight stigma: Implications for obesity prevention and treatment. Current Obesity Reports, 4(2), 182-190. https://doi.org/10.1007/s13679-015-0153-z

Schvey, N. A., Puhl, R. M., \& Brownell, K. D. (2011). The impact of weight stigma on caloric consumption. Obesity, 19(10), 1957-1962. https://doi.org/10.1038/oby.2011.204

Stunkard, A. J., \& Messick, S. (1985). The three-factor eating questionnaire to measure dietary restraint, disinhibition and hunger. Journal of Psychosomatic Research, 29(1), 71-83. https://doi.org/10.1016/0022-3999(85)90010-8

Vartanian, L. R., \& Novak, S. A. (2011). Internalized societal attitudes moderate the impact of weight stigma on avoidance of exercise. Obesity, 19(4), 757-762. https://doi.org/10.1038/oby.2010.234

Wang, S. S., Brownell, K. D., \& Wadden, T. A. (2004). The influence of the stigma of obesity on overweight individuals. International Journal of Obesity, 28(10), 1333-1337. https://doi.org/10.1038/sj.ijo.0802730

Werneke, U., Goldberg, D. P., Yalcin, I., \& Üstün, B. T. (2000). The stability of the factor structure of the General Health Questionnaire. Psychological Medicine, 30(4), 823-829.

Wott, C. B., \& Carels, R. A. (2010). Overweight stigma, psychological distress and weight loss treatment outcomes. Journal of Health Psychology, 15(4), 608-614. https://doi.org/10.1177/1359105309355339 
Weight-related psychological inflexibility, weight self-stigma, and health-related outcomes 
Weight-related psychological inflexibility, weight self-stigma, and health-related outcomes

Table 1. Zero-order correlations.

\begin{tabular}{|c|c|c|c|c|c|c|c|c|c|}
\hline Measure & 1 & 2 & 3 & 4 & 5 & 6 & 7 & 8 & 9 \\
\hline 1. WSSQ & - & - & - & - & - & - & - & - & - \\
\hline 2. AAQ-W & $.78 * * *$ & - & - & - & - & - & - & - & - \\
\hline 3. BMI & $.27 *$ & .12 & - & - & - & - & - & - & - \\
\hline $\begin{array}{l}\text { 4. TFEQ } \\
\text { Disinhibition }\end{array}$ & $.46 * * *$ & $.45 * * *$ & .01 & - & - & - & - & - & - \\
\hline $\begin{array}{l}\text { 5. TFEQ } \\
\text { Emotional Eating }\end{array}$ & $.56 * * *$ & $.65 * * *$ & .22 & $.69 * * *$ & - & - & - & - & - \\
\hline $\begin{array}{l}\text { 6. TFEQ } \\
\text { Cognitive } \\
\text { Restraint }\end{array}$ & -.13 & -.21 & -.08 & -.14 & $-.26^{*}$ & - & - & - & - \\
\hline $\begin{array}{l}\text { 7. IPAQ total } \\
\text { activity }\end{array}$ & -.02 & -.13 & -.03 & .07 & -.01 & .03 & - & - & - \\
\hline $\begin{array}{l}\text { 8. IPAQ total } \\
\text { sitting time }\end{array}$ & .17 & $.29 * * *$ & .15 & .19 & .22 & -.20 & $-.43 * * *$ & - & - \\
\hline 9. GHQ & $.52 * * *$ & $.58 * * *$ & $.22 *$ & $.25 *$ & $.46^{* * *}$ & -.17 & .02 & .08 & - \\
\hline
\end{tabular}

$* p<.05, * * p<.01, * * * p<.001$.

Note. BMI = Body Mass Index, TFEQ = Three Factor Eating Questionnaire, IPAQ = International Physical Activity Questionnaire, GHQ = General Health Questionnaire, WSSQ = Weight Self-Stigma Questionnaire, AAQ-W = Acceptance and Action Questionnaire for Weight 
Weight-related psychological inflexibility, weight self-stigma, and health-related outcomes

Table 2. Mediation analyses controlling for BMI as a covariate.

\begin{tabular}{|c|c|c|c|c|c|c|c|}
\hline \multirow[b]{2}{*}{ Outcome } & \multirow{2}{*}{$\frac{\text { a path }}{b(S E)}$} & \multirow{2}{*}{$\frac{\mathrm{b} \text { path }}{b(S E)}$} & \multirow{2}{*}{$\frac{c \text { path }}{b(S E)}$} & \multirow{2}{*}{$\frac{c^{\prime} \text { path }}{b(S E)}$} & \multicolumn{3}{|c|}{ Products of coefficients } \\
\hline & & & & & $\begin{array}{l}\text { Point } \\
\text { estimate }\end{array}$ & $\begin{array}{l}\text { Bootstrapping } \\
95 \% \text { CI }\end{array}$ & $\begin{array}{l}\text { Proportion mediated } \\
\left(1-c^{\prime} / c\right)\end{array}$ \\
\hline \multicolumn{8}{|c|}{$A A Q$-W mediating the relation between WSSQ and health outcomes } \\
\hline GHQ & $\begin{array}{l}1.646 \\
(.153)^{* * *}\end{array}$ & $\begin{array}{l}.002 \\
(.001)^{* *}\end{array}$ & $\begin{array}{l}.004 \\
(.001)^{* * *}\end{array}$ & $\begin{array}{l}.001 \\
.001)\end{array}$ & $\begin{array}{l}.004 \\
(.001)\end{array}$ & $.001, .006$ & $80 \%$ \\
\hline TFEQ-EE & $\begin{array}{l}1.646 \\
(.153)^{* * *}\end{array}$ & $\begin{array}{l}.071 \\
(.017)^{* * * *}\end{array}$ & $\begin{array}{l}.139 \\
(.025)^{* * * *}\end{array}$ & $\begin{array}{l}.021 \\
(.037)\end{array}$ & $\begin{array}{l}.117 \\
(.029)\end{array}$ & $.063, .185$ & $85 \%$ \\
\hline TFEQ-D & $\begin{array}{l}1.65 \\
(.15)^{* * *}\end{array}$ & $\begin{array}{l}.053 \\
(.044)\end{array}$ & $\begin{array}{l}.279 \\
(.059) * * *\end{array}$ & $\begin{array}{l}.192 \\
(.093)\end{array}$ & $\begin{array}{l}.087 \\
(.078)\end{array}$ & $-.051, .262$ & \\
\hline TFEQ-CR & $\begin{array}{l}1.65 \\
(.15)^{* * * *}\end{array}$ & $\begin{array}{l}-.044 \\
(.027)\end{array}$ & $\begin{array}{l}-.036 \\
(.037)\end{array}$ & $\begin{array}{l}.037 \\
(.058)\end{array}$ & $\begin{array}{l}-.073 \\
(.043)\end{array}$ & $-.159, .016$ & \\
\hline IPAQ-PA & $\begin{array}{l}1.65 \\
(.15)^{* * *}\end{array}$ & $\begin{array}{l}-.447 \\
(.274)\end{array}$ & $\begin{array}{l}-.048 \\
(.368)\end{array}$ & $\begin{array}{l}.688 \\
(.579)\end{array}$ & $\begin{array}{l}-.736 \\
(.473)\end{array}$ & $-1.715, .179$ & \\
\hline IPAQ-Sed & $\begin{array}{l}1.65 \\
(.15)^{* * * *}\end{array}$ & $\begin{array}{l}26.158 \\
(10.494) *\end{array}$ & $\begin{array}{l}17.231 \\
(14.419)\end{array}$ & $\begin{array}{l}-25.834 \\
(22.204)\end{array}$ & $\begin{array}{l}43.065 \\
(19.111)\end{array}$ & $5.927,82.077$ & $100 \%$ \\
\hline \multicolumn{8}{|c|}{ WSSQ mediating the relation between $A A Q-W$ and health outcomes } \\
\hline GHQ & $\begin{array}{l}.368 \\
(.034)^{* * *}\end{array}$ & $\begin{array}{l}.001 \\
(.001)\end{array}$ & $\begin{array}{l}.002 \\
(.001)^{* * * *}\end{array}$ & $\begin{array}{l}.002 \\
(.001)^{* *}\end{array}$ & $\begin{array}{l}.001 \\
(.001)\end{array}$ & $-.001, .002$ & \\
\hline TFEQ-EE & $\begin{array}{l}.368 \\
(.034)^{* * *}\end{array}$ & $\begin{array}{l}.021 \\
(.037)\end{array}$ & $\begin{array}{l}.079 \\
(.011)^{* * *}\end{array}$ & $\begin{array}{l}.071 \\
(.017)^{* * *}\end{array}$ & $\begin{array}{l}.008 \\
(.012)\end{array}$ & $-.015, .030$ & \\
\hline TFEQ-D & $\begin{array}{l}.368 \\
(.034)^{* * *}\end{array}$ & $\begin{array}{l}.192 \\
(.093)\end{array}$ & $\begin{array}{l}.124 \\
(.028)^{* * * *}\end{array}$ & $\begin{array}{l}.053 \\
(.044)\end{array}$ & $\begin{array}{l}.071 \\
(.037)\end{array}$ & $-.007, .142$ & \\
\hline TFEQ-CR & $\begin{array}{l}.368 \\
(.034)^{* * *}\end{array}$ & $\begin{array}{l}.037 \\
(.058)\end{array}$ & $\begin{array}{l}-.031 \\
(.017)\end{array}$ & $\begin{array}{l}-.044 \\
(.027)\end{array}$ & $\begin{array}{l}.013 \\
(.021)\end{array}$ & $-.028, .053$ & \\
\hline IPAQ-PA & $\begin{array}{l}.368 \\
(.034) * * *\end{array}$ & $\begin{array}{l}.688 \\
(.579)\end{array}$ & $\begin{array}{l}-.194 \\
(.172)\end{array}$ & $\begin{array}{l}-.447 \\
(.274)\end{array}$ & $\begin{array}{l}.253 \\
(.239)\end{array}$ & $-.228, .713$ & \\
\hline IPAQ-Sed & $\begin{array}{l}.368 \\
(.034) * * *\end{array}$ & $\begin{array}{l}-25.834 \\
(22.204)\end{array}$ & $\begin{array}{l}16.658 \\
(6.607)^{*}\end{array}$ & $\begin{array}{l}26.158 \\
(10.494)^{*}\end{array}$ & $\begin{array}{l}-9.500 \\
(8.505)\end{array}$ & $-24.081,10.504$ & \\
\hline
\end{tabular}

$* p<.05 ; * * p<.01 ; * * * p<.001$. a path $=$ Predictor and mediator, $\mathrm{b}$ path $=$ Mediator and outcome controlling for predictor, $\mathrm{c}$ path $=$ Predictor and outcome, $\mathrm{c}^{\prime}$ path $=$ Predictor and outcome controlling for mediator. $b$ coefficients and $S E$ values are reported for paths tested. Each row is a separate mediation model.

Note. AAQ-W = Acceptance and Action Questionnaire for Weight, TFEQ-EE = Three Factor Eating Questionnaire Emotional Eating subscale, WSSQ = Weight Self-Stigma Questionnaire, TFEQ-I = Three Factor Eating Questionnaire-Disinhibition, GHQ = General Health Questionnaire; IPAQ-PA = International Physical Activity Questionnaire - Physical Activity time; IPAQ-Sed = International Physical Activity Questionnaire - Sedentary time 